\title{
DNA methylation of the Monoamine Oxidases A and B genes in postmortem brains of subjects with schizophrenia
}

\author{
Qiaohui Yang ${ }^{1}$, Keiko Ikemoto ${ }^{1}$, Satoshi Nishino ${ }^{1}$, Junko Yamaki ${ }^{2}$, Yasuto Kunii ${ }^{1}$, Akira Wada ${ }^{1}$, \\ Yoshimi Homma ${ }^{2}$, Shin-Ichi Niwa ${ }^{{ }^{*}}$ \\ ${ }^{1}$ Department of Neuropsychiatry, School of Medicine, Fukushima Medical University, Fukushima, Japan \\ ${ }^{2}$ Department of Biomolecular Science, School of Medicine, Fukushima Medical University, Fukushima, Japan \\ Email: ${ }^{\text {si-niwa@,fmu.ac.jp }}$
}

Received 30 September 2012; revised 28 October 2012; accepted 7 November 2012

\begin{abstract}
Aims: We focused on DNA methylation of the promoter regions of the Monoamine Oxidase (MAO) $A$ and $B$ genes from postmortem brains of subjects with schizophrenia. Methods: We determined levels of DNA methylation using genomic DNA samples purified from four brain areas: prefrontal cortex (PFC), hippocampus, occipital cortex and nucleus accumbens (NAc), by a bisulfite sequencing method from seven normal subjects and six subjects with schizophrenia. Results: Although very few methylated CpGs of the $M A O A$ and $M A O B$ genes were detected in male samples, various DNA methylation patterns were present in female samples, and some differences were found in such patterns between normal subjects and subjects with schizophrenia. In the PFC, the average level of methylation of both genes was significantly higher in subjects with schizophrenia than in normal subjects. The content of highly methylated alleles of the MAOA gene in the NAc was significantly associated with schizophrenia, with similar results obtained for the MAOB gene in both the NAc and PFC. Some CpG sites showed higher levels of methylation in schizophrenia than in normal subjects. Conclusions: Levels of methylation were quite high in NAc and PFC in female subjects with schizophrenia compared with those in female normal subjects.
\end{abstract}

Keywords: DNA Methylation; Monoamine Oxidase; Nucleus Accumbens; Postmortem Brain; Schizophrenia

\section{INTRODUCTION}

The causes of schizophrenia remain unclear, despite intense research. Extensive studies on disease-susceptibility genes have focused on functional polymorphisms that induce alterations to the encoded amino acid sequences.

${ }^{*}$ Corresponding author.
However, the results of multiple linkage analyses have not clarified the underlying etiological factors associated with schizophrenia.

Epigenetic modifications of chromatin are widely accepted to play key roles in the regulation of gene expression, in both the activation and silencing of genes. In higher eukaryotes, DNA is methylated at cytosines located 5' to guanosine in the $\mathrm{CpG}$ dinucleotide [1]. This modification has important regulatory effects on gene expression, particularly when involving CpG-rich areas known as $\mathrm{CpG}$ islands, located in the promoter regions of many genes [2,3]. Extensive methylation of $\mathrm{CpG}$ islands has been associated with transcriptional inactivation of selected imprinted genes $[4,5]$ and genes on the inactive $\mathrm{X}$ chromosome of females [6,7].

Evidence has been accumulated from substantial observations of identical twins that epigenetic factors play important roles in the pathogenesis of schizophrenia [8]. Recent studies using postmortem brains of schizophrenia subjects have provided novel findings indicating that epigenetic factors are associated with biological markers that appear to be aberrantly regulated in the brains of subjects with schizophrenia [9-11].

Monoamine Oxidases (MAOs) are enzymes of the mitochondrial outer membrane, and are present as two isoforms, $M A O A$ and $M A O B[12,13]$. These enzymes are encoded by separate genes that are closely linked in opposite orientation on the $\mathrm{X}$ chromosome. MAOA and $M A O B$ exhibit distinct differences in substrate selectivity and inhibitor sensitivity and play different roles in neurotransmitter metabolism and behavior. MAOA shows a preference for serotonin, norepinephrine, and epinephrine as substrates, whereas $M A O B$ shows a preference for phenylethylamine. Both isoforms break down dopamine. Regional localization of $M A O A, M A O B$ positive fibers, terminals and glia were found in many brain areas including cerebral cortex, corpus striatum and hippocampus [14].

Early in 1970's, reduced MAO activity was reported in 
the blood platelets of schizophrenic patients [15] and they later suggested that reduced MAO activity might be a genetic marker for vulnerability to schizophrenia [16]. The loss of both MAO genes may be involved in the severe mental retardation of some subjects with Norrie disease [17], and the MAOA gene has been considered a candidate gene in various central nervous system disorders including abnormally exaggarated aggression [18-20] and attention deficit hyperactivity disorder [21-23]. Since the MAO genes are located on the $\mathrm{X}$ chromosome, males inherit a single allele, and thus display a hemizygous genotype. In females, random transcriptional silencing of one of the two X chromosomes occurs as dosage compensation during late blastocyst development [24,25].

To assess epigenetic factors in schizophrenia, as a first step we used the method of bisulfite sequencing to determine patterns of methylation in genomic DNA extracted from postmortem brains. We chose the promoter regions of the $M A O A$ and $M A O B$ genes for this analysis, since these genes are on the $\mathrm{X}$ chromosome, and $\sim 50 \%$ methylated alleles can be expected in female samples. We further compared patterns of methylation in four different brain regions. The results of this study suggest that postmortem brains are quite useful for analyzing DNA methylation with the bisulfite sequencing method, and that methylation patterns may vary among regions of brain in female normal subjects and female subjects with schizophrenia.

\section{METHODS}

\subsection{Ethics Statement}

The study was conducted in accordance with the Decla- ration of Helsinki and approved by the Ethics Committee of the Fukushima Medical University. All subjects participated after giving informed written consent.

\subsection{Subjects}

Postmortem brain tissues of six subjects with schizophrenia were donated by the Postmortem Brain Bank of Fukushima for Psychiatric Research, including tissue from six individuals who had previously been diagnosed with schizophrenia. Postmortem brain tissues of seven normal subjects were obtained from the brain bank of The Netherlands. Schizophrenia was diagnosed according to the Diagnostic and Statistical Manual of Mental Disorders fourth edition (DSM-IV). We obtained brain tissues from four different regions of postmortem brain: Brodmann area 9/46 (BA9/46) of prefrontal cortex (PFC) which is implicated in higher cognitive functions [26]; hippocampus (HIP) which is associated with delusions and hallucinations [27]; nucleus accumbens (NAc) where dopamine degrading enzyme, MAOB was highly expressed in the rodent [28] and BA19 of occipital cortex (OCC). In all cases, tissue samples were stored at $-80^{\circ} \mathrm{C}$ prior to experiment. Cases with a significant history of drug or alcohol abuse or neurological disorder, head injury, or a postmortem interval (PMI) of $>48 \mathrm{~h}$ were excluded. No significant difference in age at death was seen between normal subjects and subjects with schizophrenia. Additional demographic data including sex, age, cause of death, PMI, subtype of disease, doses of antipsychotic medications, and disease duration are summarized in Table 1.

Table 1. Clinical characteristics of the presently examined subjects.

\begin{tabular}{|c|c|c|c|c|c|c|c|c|}
\hline Sex & Subject & No. & Subtype & $\begin{array}{c}\text { Age } \\
\text { (years) }\end{array}$ & $\begin{array}{c}\text { PMI } \\
\text { (h) }\end{array}$ & Cause of death & $\begin{array}{c}\text { CP } \\
\text { (mg equivalent) }\end{array}$ & $\begin{array}{c}\text { Disease } \\
\text { duration (years) }\end{array}$ \\
\hline \multirow[t]{8}{*}{ Female } & Normal subjects & 1 & & 60 & 8.5 & Lung carcincoma & & \\
\hline & & 2 & & 80 & 6.5 & Dehydration & & \\
\hline & & 3 & & 77 & 5.5 & $\begin{array}{l}\text { Lung metastases from a brest } \\
\text { carcinoma }\end{array}$ & & \\
\hline & & 4 & & 73 & 14 & $\begin{array}{l}\text { Respiratory insufficiency with } \\
\text { severe COPD and urinary tract } \\
\text { infection }\end{array}$ & & \\
\hline & & 5 & & 64 & 9 & Probable ileus & & \\
\hline & Subjects with schizophrenia & 6 & Undifferentiated & 74 & 26 & Pneumonia & 190 & 37 \\
\hline & & 7 & Paranoid & 68 & 15 & Chronic renal failure & 325 & 40 \\
\hline & & 8 & Paranoid & 76 & 25 & Pneumonia & 114 & 48 \\
\hline \multirow{4}{*}{ Male } & & 10 & & 88 & 6 & Cardiac arrest & & \\
\hline & Subjects with schizophrenia & 11 & Undifferentiated & 70 & 7 & Cancer of head of pancreas & 550 & 39 \\
\hline & & 12 & Undifferentiated & 75 & 17 & Pneumonia & 225 & 47 \\
\hline & & 13 & Undifferentiated & 66 & 7 & Pneumonia & 0 & 36 \\
\hline
\end{tabular}

Abbreviations: No.: number; PMI, postmortem intervals; CP: Chlorpromazine converted. 


\subsection{Bisulfite Sequencing Analysis}

Genomic DNA was extracted using a Blood \& Cell Culture DNA Midi Kit (Qiagen GmbH, Hilden, Germany) and subsequently employed for bisulfate-assisted sequencing. Bisulfite modification of genomic DNA was performed as described previously [29]. Briefly, $5 \mu \mathrm{g}$ of genomic DNA suspended in $50 \mu \mathrm{L}$ of water was incubated at $95^{\circ} \mathrm{C}$ for $10 \mathrm{~min}$, and then at $37^{\circ} \mathrm{C}$ for $30 \mathrm{~min}$ with $1.5 \mu \mathrm{L}$ of $10 \mathrm{M} \mathrm{NaOH}$. The solution was further incubated overnight at $55^{\circ} \mathrm{C}$ following the addition of $310 \mu \mathrm{L}$ of $5 \mathrm{M}$ sodium bisulfite, $2.5 \mu \mathrm{L}$ of $0.1 \mathrm{M}$ hydroquinone, and $136 \mu \mathrm{L}$ of water in a final volume of 500 $\mu \mathrm{L}$. After modification, DNA was purified using a Wizard DNA clean-up System (Promega BioSciences, San Luis Obispo, CA, USA), and desulfonated with $0.3 \mathrm{M}$ $\mathrm{NaOH}$ for $15 \mathrm{~min}$ at $37^{\circ} \mathrm{C}$. The bisulfite-treated DNA was then amplified by polymerase chain reaction (PCR) using the following primers:

5'-ATTTTTAGTGTTTAGTTTTTTTTGGGGTTT-3'

(MAOA sense, -318 to -289 ) (GenBank ID: NM-000240) and 5'-AAAAAAACCCTTCTATCAACTCCCC-3'

(MAOA antisense, +125 to +101$)$, and

5'-TGTATTAGGGAGGTTGATGGGAAAA TAT-3'

(MAOB sense, -198 to -171 ) (GenBank ID: NM-000898) and 5'-CTCCCCCAAACAACCACCTATC-3' (MAOB antisense, +286 to +265 ). PCR amplification of MAOA was performed for 40 cycles of $30 \mathrm{~s}$ at $95^{\circ} \mathrm{C}, 1 \mathrm{~min}$ at $63^{\circ} \mathrm{C}$, and $90 \mathrm{~s}$ at $72^{\circ} \mathrm{C}$, with a final extension at $72^{\circ} \mathrm{C}$ for $10 \mathrm{~min}$. PCR amplification of $M A O B$ included 40 cycles of $30 \mathrm{~s}$ at $95^{\circ} \mathrm{C}, 1 \mathrm{~min}$ at $55^{\circ} \mathrm{C}$, and $90 \mathrm{~s}$ at $72^{\circ} \mathrm{C}$, with a final extension at $72^{\circ} \mathrm{C}$ for $10 \mathrm{~min}$. PCR products were then cloned using the TOPO TA cloning Kit (Invitrogen, Carlsbad, CA, USA), and $\geq 10$ clones for each independent sample were sequenced.

\subsection{Statistical Analyses}

Statistical significance between two groups and among multiple groups was evaluated using Student's t-test and Tukey-Kramer test after F-test or one-way analysis of variance, respectively. All values are expressed as the mean \pm standard error of the mean (s.e.m.).

\section{RESULTS}

\subsection{DNA Methylation Status of MAOA and $M A O B$ Genes in Four Brain Areas}

To address the involvement of DNA methylation status of $M A O A M A O B$ genes in schizophrenia, we examined DNA methylation in different regions of postmortem brains of normal subjects and subjects with schizophrenia (Table 1). Some $\mathrm{CpG}$ islands are found in the 5' regulatory region of the human MAOA (Figure 1(a)) and $M A O B$ (Figure 1(b)) genes, and we examined the DNA methylation status of $\mathrm{CpG}$ islands containing a transla-

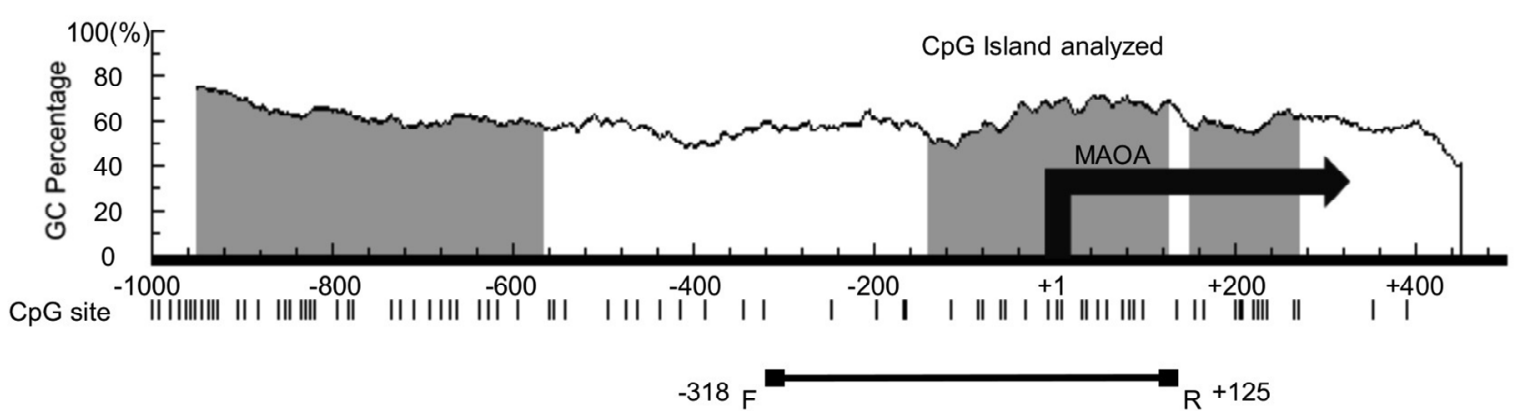

(a)

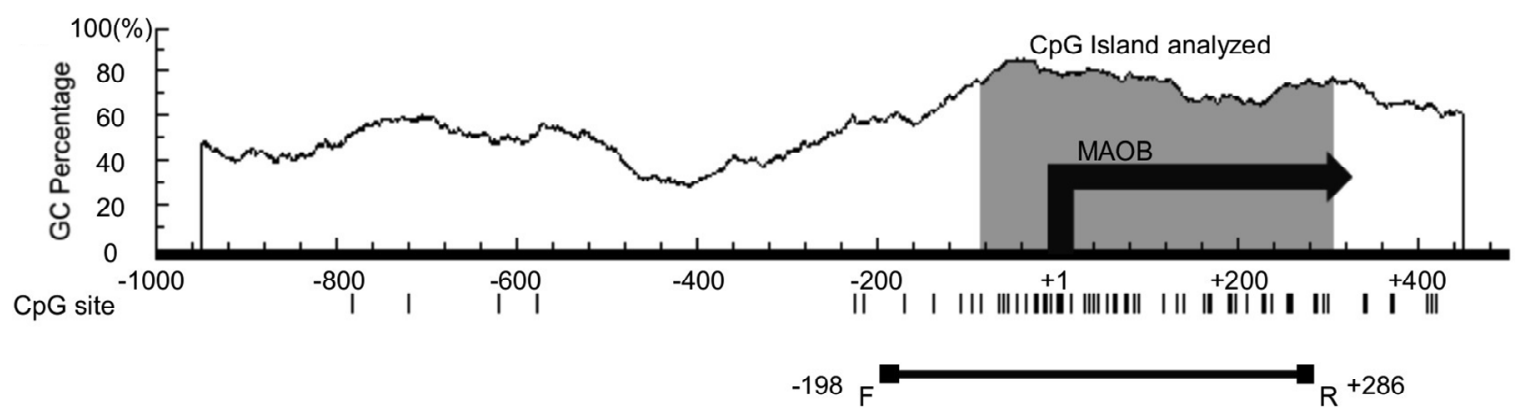

(b)

Figure 1. Schematic diagram of the 5' regulatory regions of the human $M A O A$ (a) and $M A O B$ (b) genes. Vertical bars indicate $\mathrm{CpG}$ dinucleotide positions. GC contents (\%), position of $\mathrm{CpG}$ island (grey area), and the transcription start site $(+1)$ are shown. The areas examined in this study are indicated by horizontal lines with boxes. There are 21 and $46 \mathrm{CpG}$ sites in the $-318-+125$ region of $M A O A$ and the $-198-+286$ region of $M A O B$, respectively. 
tion start site, around where the methylation of $\mathrm{CpG}$ sites will affect the transcription of genomic DNA directly.

Genomic DNA samples were prepared from four dif- ferent brain regions in each case, and at least 10 methylation patterns were collected from each DNA sample (Figure 2). Methylation patterns were confirmed in al-

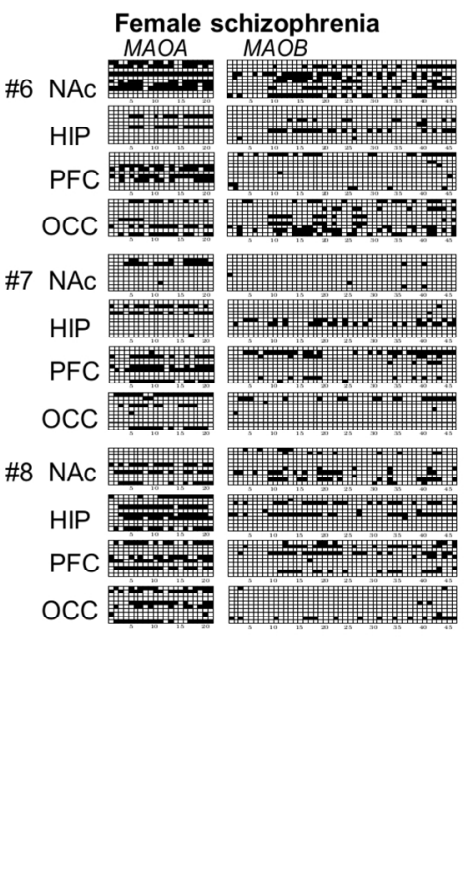

(b)

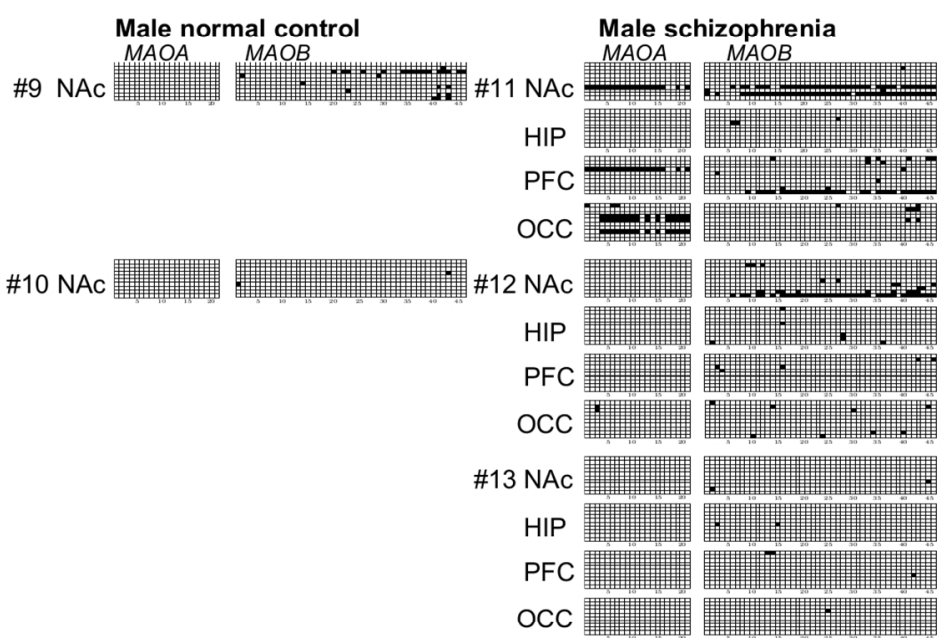

(d)

Figure 2. Promoter methylation of $\mathrm{CpG}$ sites in females and males. (a) Methylation status of four brain regions derived from 5 normal female subjects. (b) Methylation status of four brain regions from 3 female subjects with schizophrenia. (c) Methylation status of NAc samples derived from 2 normal male subjects. (d) Methylation status of four different brain regions derived from 3 male subjects with schizophrenia. Brain samples were obtained from four different regions: nucleus accumbens (NAc); hippocampus (HIP); prefrontal cortex (PFC); and occipital cortex (OCC). Genomic DNA was prepared and DNA methylation in MAOA (left) and $M A O B$ (right) promoter regions was determined by bisulfite sequencing. At least 10 clones were sequenced for each sample, and the methylation status of 10 independent alleles is shown as a representative finding. Open and closed squares indicate unmethylated and methylated CpGs, respectively. 
leles from either active or inactive $\mathrm{X}$ chromosomes without distinction. In females, various patterns of methylation were observed in samples from normal subjects (Figure 2(a)) and subjects with schizophrenia (Figure 2(b)). Many non-methylated alleles and a few 100\%-methylated alleles in which all $\mathrm{CpG}$ sites were methylated were observed. Among DNA samples tested, overall level of methylation varied from 48\% (MAOA, HIP, normal subject \#2) to $0 \%$ (MAOA, NAc, normal subjects $\# 1$, \#2, and \#4). Conversely, levels of methylation for both MAOA and MAOB genes were quite low in males (Figures 2(c) and (d)). Although only DNA samples from NAc of 2 male normal subject brains (Figure 2(c)) were analyzed, no methylation sites were detected in the MAOA gene, and a little extent of DNA methylation was seen in the $M A O B$ gene. Similar results were obtained for four different brain regions of 3 male subjects with

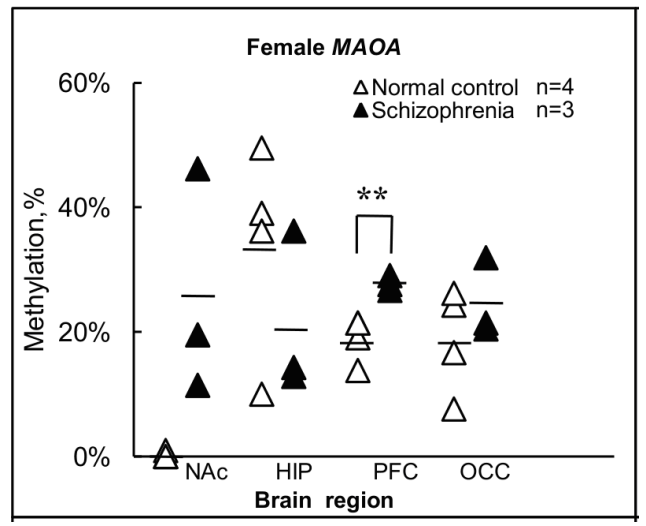

(a)

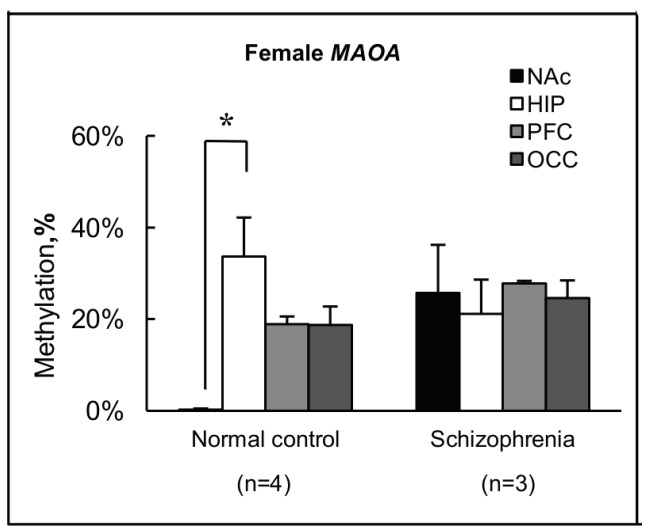

(c) schizophrenia (Figure 2(d)). Some highly methylated alleles of the MAOA gene were observed in NAc, PFC, and OCC, and of the MAOB gene in NAc and PFC in males (Figures 2(c) and (d)).

As few methylated $\mathrm{CpG}$ sites were observed in both $M A O A$ and $M A O B$ genes of normal subjects and subjects with schizophrenia among males, we focused on the comparison of methylation of $M A O A$ and $M A O B$ genes between the two groups in females.

\subsection{Total Level of Methylation in Each Brain Area in Females}

The findings for methylation in females shown in Figures 2(a) and (b) are summarized in terms of brain regions in normal subjects and subjects with schizophrenia in Figure 3. For the $M A O A$ gene, overall levels of methylation

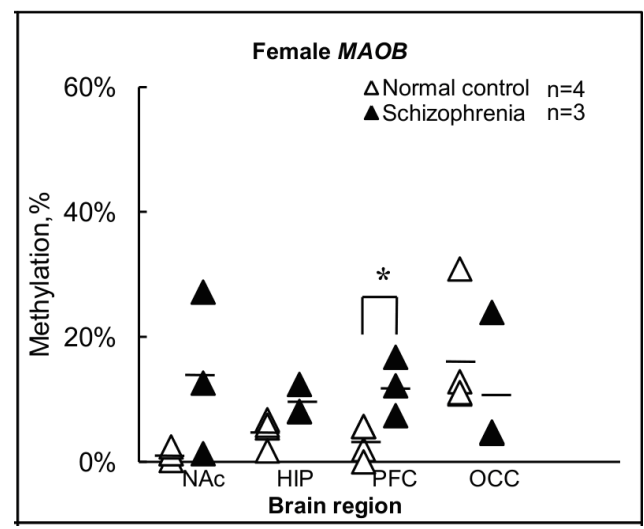

(b)

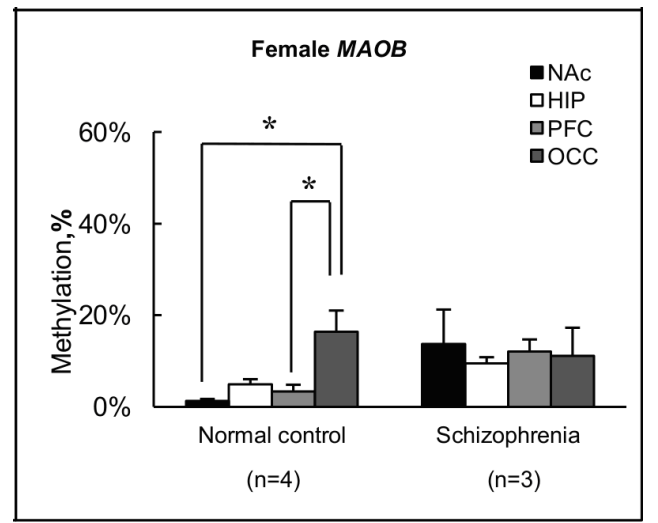

(d)

Figure 3. Summary of levels of methylation in female. (a) Levels of methylation for the MAOA gene in each brain region were calculated from individual results, and expressed as the mean \pm s.e.m.; (b) Levels of methylation for the $M A O B$ gene in each brain region were calculated from individual results, and expressed as the mean \pm s.e.m. Open and closed triangles indicate results for female normal subjects and female subjects with schizophrenia, respectively. Significance of differences was evaluated using Student's t-test $\left({ }^{* *} \mathrm{p}<0.01,{ }^{*} \mathrm{p}<0.05\right)$; (c) Levels of methylation for the $M A O A$ gene in female normal subjects and female subjects with schizophrenia were calculated from individual results, and expressed as mean \pm s.e.m.; (d) Levels of methylation for the $M A O B$ gene in female normal subjects and female subjects with schizophrenia were calculated from individual results, and expressed as mean \pm s.e.m. Four different color columns indicate results for four different brain regions: NAc; HIP; PFC and OCC in normal subjects and subjects with schizophrenia, respectively. Significance of differences was evaluated with Student's t-test $\left({ }^{*} \mathrm{p}<0.05\right)$. 
were $<1 \%(0 \%-0.95 \%)$ in all NAc samples derived from normal subject brains, but $26 \%$ (range, $11 \%$ - 46\%) in NAc of subjects with schizophrenia (Figures 3(a) and (c)). Notably, almost no methylation was observed in normal subject NAc, although no significant difference was apparent between control and schizophrenic groups in level of methylation in NAc (Figure 3(a)). Similar results were obtained for the $M A O B$ gene (Figures 3(b) and (d)). In NAc, levels of methylation of the $M A O B$ gene were low $(0.22 \%-2.4 \%)$ in normal subject, but varied among schizophrenia from $1.3 \%$ to $27 \%$ (Figure 3(b)). Conversely, a significant difference $(\mathrm{p}<0.01)$ in $M A O A$ gene methylation in PFC was seen between the two groups, with $19 \%(14 \%-21 \%)$ in normal subjects and $28 \%(27 \%-29 \%)$ in subjects with schizophrenia (Figure 3(a)). A significant difference $(p<0.05)$ between groups was also detected in $M A O B$ gene methylation in PFC, with $3.3 \%(0 \%-5.7 \%)$ in normal subjects and $12 \%(7.4 \%-17 \%)$ in subjects with schizophrenia (Figure 3(b)). However, we detected no significant difference between the two groups in terms of methylation in HIP or OCC. Conversely, we found differences in methylation status among the four regions examined in normal subjects (Figures 3(c) and (d)). In particular, level of methylation in NAc was lower than that in HIP for the MAOA gene (Figure 3(c)), while levels of methylation in NAc and PFC were lower than in OCC for the $M A O B$ gene (Figure 3(d)). However, no differences in methylation status were found among brain regions in subjects with schizophrenia.

\subsection{Degrees of $M A O A$ and $M A O B$ Allele Methylation in Four Brain Regions among Female Subjects}

We next compared the appearance of highly methylated alleles in normal and schizophrenic brains in females. We defined alleles in which $>30 \%$ of $\mathrm{CpG}$ sites within each allele were methylated as highly methylated alleles and counted the number of such sites for four brain areas in the two groups. A significant difference was observed between groups in the frequency of highly methylated alleles in NAc for MAOA gene and in NAc and PFC for $M A O B$ gene, while no significant difference between groups was found for HIP and OCC. In the case of the MAOA gene, $0 / 40(0 \%)$ and $11 / 30(33 \%)$ of all alleles in NAc were highly methylated in normal subjects and subjects with schizophrenia, respectively (Fisher, $\mathrm{p}=$ $0.000)$. Similar results were obtained for the $M A O B$ gene, with $0 / 40(0 \%)$ and $8 / 30(27 \%)$ of all alleles in NAc (Fisher, $\mathrm{p}=0.001$ ), and $0 / 40(0 \%)$ and $5 / 30(17 \%)$ of all alleles in PFC (Fisher, $p=0.012$ ) highly methylated in normal subjects and subjects with schizophrenia, respectively.

\subsection{DNA Methylation Analysis for Each CpG Site}

We further compared overall levels of methylation in terms of each $\mathrm{CpG}$ site for the MAOA and MAOB genes in normal subjects and subjects with schizophrenia (Figure 4), and some significant differences between groups were found in $M A O A$ within NAc and PFC, and $M A O B$ within HIP and PFC.

\subsection{Correlation between Dosage and DNA Methylation}

Lastly, we examined possible drug effects on methylation of $M A O A$ and $M A O B$ genes, and no correlation was seen between the chlorpromazine-converted (CP) neuroleptic dosage and the degree of DNA methylation of MAOA and $M A O B$ genes.

\section{DISCUSSION}

The present study successfully analyzed DNA methylation using DNA samples purified from various regions of postmortem brain with a bisulfite sequencing method, and demonstrated that various patterns of methylation are present in DNA samples and that levels of methylation differ between the sexes and among brain regions in normal subjects and subjects with schizophrenia. Although very few methylated CpGs were present in regions of the DNA samples examined in males (Figures 2(c) and (d)), in the case of females, levels of methylation were quite low in NAc in normal subjects, and a significant difference in methylation at PFC was detected between normal subjects and subjects with schizophrenia. These are novel and invaluable epigenetic findings. Further surveys of differentially methylated genes could increase our understanding of altered gene expression and clinical phenotypes in schizophrenia.

\subsection{Methylation Level of MAO Genes on $X$ Chromosome and $\mathrm{X}$-Inactivation}

We expected methylation levels of $\sim 50 \%$, since one $\mathrm{X}$ chromosome in females is methylated and inactivated. As expected, we detected levels of methylation varying from $0 \%$ to $50 \%$ among genes and regions of the brain in females. In particular, one striking finding was that levels of methylation in both $M A O A$ and $M A O B$ genes were extremely low in NAc of normal subjects (Figures 3(a) and (b)). These low levels of methylation were also observed in the $M A O B$ gene in other regions of brain of normal subjects. These findings indicate that not all $\mathrm{CpG}$ sites are always methylated on the inactivated $\mathrm{X}$ chromosome in females, and suggest that methylation level varies among cell types and brain regions in humans. In this respect, Carrel and Willard have reported important 


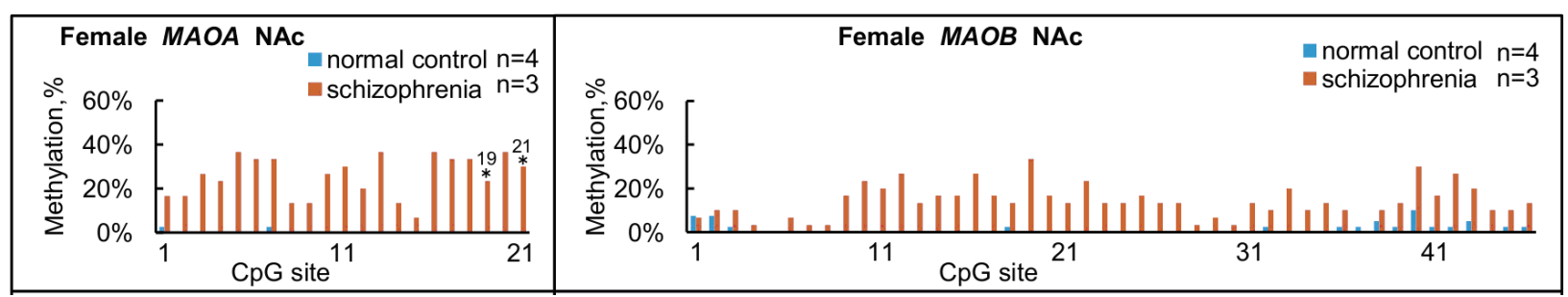

(a)

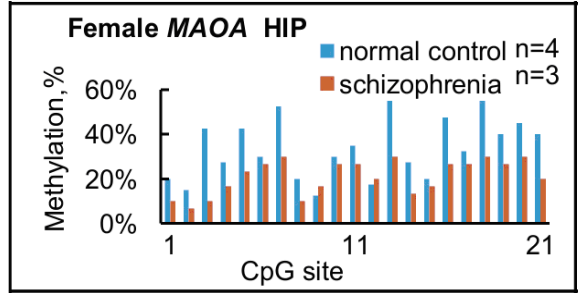

(b)

(e)

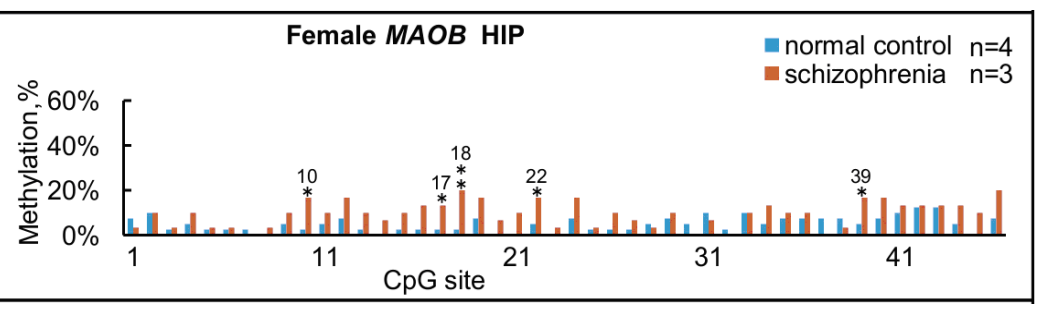

(f)

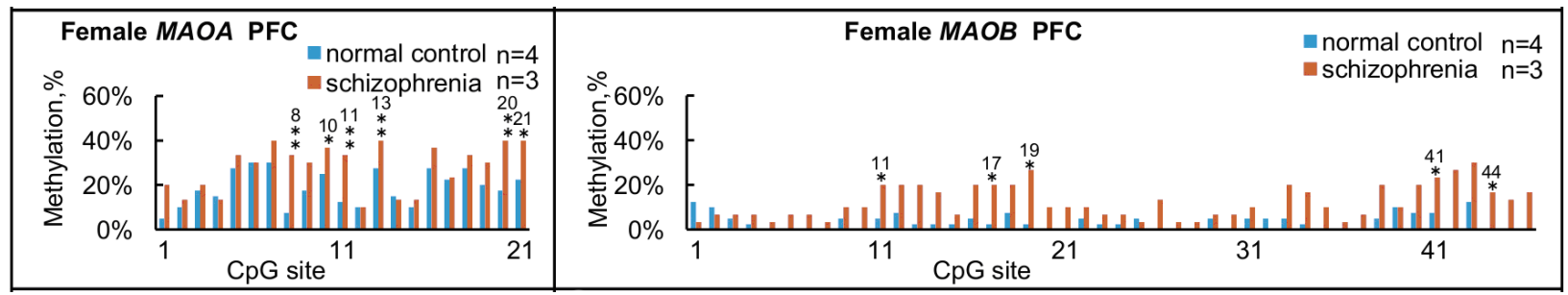

(c)

(g)

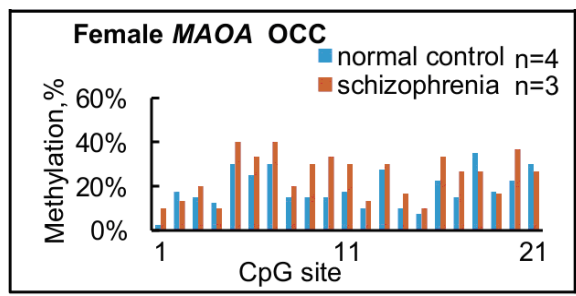

(d)

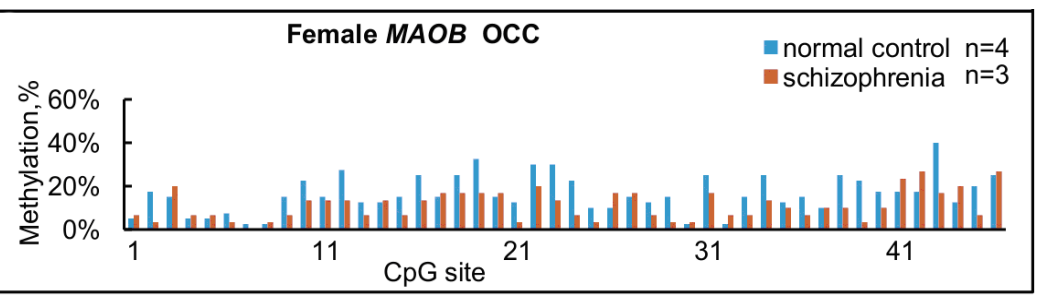

(h)

Figure 4. Summary of methylation status at each $\mathrm{CpG}$ site in females. Overall levels of methylation at each $\mathrm{CpG}$ site for $M A O A$ (left panels) and $M A O B$ (right panels) were calculated from the results shown in Figure 2, and compared among the four brain regions from normal subjects and subjects with schizophrenia. (a) and (e) NAc; (b) and (f) HIP; (c) and (g) PFC, (d) and (h) OCC. Significant differences in MAOA are found in NAc at No. 19 and $21 \mathrm{CpG}$ sites; in PFC at No. 8, 10, 11, 13, 20 and $21 \mathrm{CpG}$ sites. Significant differences in $M A O B$ are found in the HIP at No. 10, 17, 18, 22 and 39 CpG sites; in PFC at No. 11, 17, 19, 41, and at $44 \mathrm{CpG}$ sites. ${ }^{*} \mathrm{p}<0.05$ and ${ }^{* *} \mathrm{p}<0.01$. The number over ${ }^{*}$ or ${ }^{* *}$ represents the number of $\mathrm{CpG}$ sites.

findings on heterogeneity of expression in the female $\mathrm{X}$ chromosome in 2005 [30]. About $15 \%$ of X-linked genes were found to escape inactivation to some extent, and the proportion of genes escaping inactivation differed among regions of the $\mathrm{X}$ chromosome. In addition, $10 \%$ of $\mathrm{X}$-linked genes exhibited variable patterns of inactivation and were expressed to various extents on some inactive chromosomes. Since MAO genes are located quite close to the region reported to escape X-inactivation, our finding that levels of methylation of MAO genes in all DNA samples examined were much lower than $50 \%$ is understandable.

On the other hand, we detected only a few methylated CpGs in male samples. According to twins study, the methylation level of MAOA gene is also low in male sample [31]. It is necessary to clarify other regulatory mechanisms for male subjects. For example, in $2009 \mathrm{Wu}$ et al. found that a transcriptional complex encoded by the sex-determining region $\mathrm{Y}(S R Y)$ gene located on the $\mathrm{Y}$ chromosome and the specificity protein 1 gene located on chromosome 12 play significant roles in MAO production in the $\mathrm{BE}(2) \mathrm{C}$ human male neuroblastoma cell line [32].

\subsection{Methylation Level for MAOs is Higher in Schizophrenia than in Normal Subjects}

An association of aberrant DNA methylation in post- 
mortem brains with the pathogenesis of schizophrenia has recently been demonstrated by Grayson et al. in 2005 [33]. They noted that down-regulation of glutamic acid decarboxylase 67 and reelin at both mRNA and protein levels was the most consistently replicated finding in the postmortem cortex from subjects with schizophrenia, and finally concluded that hypermethylation in the promoter of the reelin gene is a major cause of such down-regulation. The present study detected some differences in DNA methylation in the MAO genes between normal and schizophrenic brains, although little direct evidence has suggested that MAO gene products are involved in producing the phenotype of schizophrenia. In our study, in PFC, levels of methylation in both the MAOA gene ( $p$ $<0.01)$ and $M A O B$ gene $(\mathrm{p}<0.05)$ were significantly higher in subjects with schizophrenia than in normal subjects (Figures 3(a) and (b)). Moreover, levels of methylation in NAc from schizophrenic brains varied from $11 \%$ to $46 \%$, while levels in all normal subjects NAc regions $(n=4)$ were at trace level $(<1 \%)$, although no significant difference between groups was observed (Figures 3(a) and (b)). In both MAOA and MAOB genes, significant differences were found in level of methylation of $\mathrm{CpG}$ sites between normal subjects and subjects with schizophrenia in PFC (Figure 4). This finding is consistent with the significant difference found in total level of methylation in PFC between normal subjects and subjects with schizophrenia (Figures 3(a) and (b)). Regions with many highly methylated $\mathrm{CpG}$ sites might be involved in the regulation of transcription, and further studies are needed to address this issue. An inverse correlation has been found between the percentage of highly methylated alleles and expression level of SRY-box containing gene 10, an oligodendrocyte-specific transcription factor [34]. This study also found that highly methylated alleles were more frequent in subjects with schizophrenia than in normal subjects in NAc in the case of the MAOA gene, and in NAc and PFC in the case of the $M A O B$ gene.

\subsection{Methylation Level Does Not Correlate with Dosage of Antipsychotic Agents}

Both MAOA and MAOB antibodies gave significant specific staining of cells and subcellular structures in human brain tissue, but the cell distribution of staining was completely different and correlated with known monoamine cell groups [35]. We found differences in level of methylation among the four brain regions examined in normal subjects, but not in subjects with schizophrenia (Figures 3(c) and (d)). The results of our study suggested that the methylation of genomic DNA might be one of the mechanisms to control the expression level of $M A O A$ and $M A O B$ in brain tissue. Aberrant methylation of genomic DNA thus appears to be detectable in sub- jects with schizophrenia, and a survey of this in greater detail will aid the understanding of the pathogenesis of schizophrenia, and in turn may yield novel strategies for drug development. To test the possibility that the present findings were due to pharmacotherapies that the subjects received, we examined the relationship between amounts of drugs used to treat schizophrenia and degree of methylation, but found no correlations.

\subsection{Methodological Limitations}

This study had several limitations. First, our finding in this study is made on a relatively older and smaller population and different race as shown in table1. It is still possible that the aging changes of the brain and different race have some effects on the DNA methylatin of MAO. Further studies are warranted to examine the DNA methylation of MAO in postmortem brains of larger cohorts with the same race. Second, we have not yet succeeded in identifying cells expressing MAO proteins in humans because of the poor quality of antibodies available

\section{CONCLUSION}

In summary, we successfully determined DNA methylation of genomic DNA samples purified from postmortem brains by a bisulfite sequencing method. Our findings revealed various patterns of methylation of the MAOA and $M A O B$ genes in DNA samples, and demonstrated that levels of methylation differ between the sexes and among brain regions in normal subjects and subjects with schizophrenia. Overall levels of methylation were quite low in NAc and PFC in female normal subjects compared with those in female subjects with schizophrenia. Since methylation in the 5' regulatory region of genes may affect the level of expression, further studies are needed to determine the levels and specific expression of $M A O A$ and $M A O B$ proteins in different types of cells in NAc and PFC of postmortem brain.

\section{ACKNOWLEDGEMENTS}

This study was supported by the brain bank of The Netherlands and the Fukushima Brain Bank. We are deeply grateful to Professor Tatsuo Suzutani for virus checks. This work was partly supported by Grant-in-Aid for Scientific Research from the Japan Society for the Promotion of Science (C-17591225; Chair Researcher, Keiko Ikemoto) and by a grant from the Fukushima Society for the Promotion of Medical Science to Qiaohui Yang. The funders had no role in study design, data collection and analysis, decision to publish, or preparation of the manuscript.

\section{REFERENCES}

[1] Holliday, R. and Grigg, G.W. (1993) DNA methylation 
and mutation. Mutation Research, 285, 61-67. doi:10.1016/0027-5107(93)90052-H

[2] Bird, A.P. (1986) CpG-rich islands and the function of DNA methylation. Nature, 321, 209-213. doi: $10.1038 / 321209 \mathrm{a} 0$

[3] Bird, A. (1992) The essentials of DNA methylation. Cell, 70, 5-8. doi:10.1016/0092-8674(92)90526-I

[4] Li, E., Beard, C. and Jaenisch, R. (1993) Role for DNA methylation in genomic imprinting. Nature, 366, 362-365. doi: $10.1038 / 366362 \mathrm{a} 0$

[5] Tremblay, K.D., Saam, J.R., Ingram, R.S., Tilghman, S.M. and Bartolomei, M.S. (1995) A paternal-specific methylation imprint marks the alleles of the mouse H19 gene. Nature Genetics, 9, 407-413. doi:10.1038/ng0495-407

[6] Pfeifer, G.P., Steigerwald, S.D., Mueller, P.R., Wold, B. and Riggs, A.D. (1989) Genomic sequencing and methylation analysis by ligation mediated PCR. Science, 246, 810-813. doi:10.1126/science. 2814502

[7] Riggs, A.D. and Pfeifer, G.P. (1992) X-chromosome inactivation and cell memory. Trends in Genetics, 8, 169-174.

[8] Cardno, A.G. and Gottesman, I.I. (2000) Twin studies of schizophrenia: From bow-and-arrow concordances to star wars Mx and functional genomics. American Journal of Medical Genetics, 97, 12-17.

doi:10.1002/(SICI)1096-8628(200021)97:1<12::AID-AJ $\mathrm{MG} 3>3.0 . \mathrm{CO} ; 2-\mathrm{U}$

[9] Impagnatiello, F., Guidotti, A.R., Pesold, C., Dwivedi, Y., Caruncho, H., Pisu, M.G., Uzunov, D.P., Smalheiser, N.R., Davis. J.M., Pandey, G.N., Pappas, G.D., Tueting, P., Sharma, R.P. and Costa, E. (1998) A decrease of reelin expression as a putative vulnerability factor in schizophrenia. Proceedings of the National Academy of Sciences of the United States of America, 95, 1571815723 .

[10] Guidotti, A., Auta, J., Davis, J.M., Di-Giorgi-Gerevini, V., Dwivedi, Y., Grayson, D.R., Impagnatiello, F., Pandey, G., Pesold, C., Sharma, R., Uzunov, D. and Costa, E. (2000) Decrease in reelin and glutamic acid decarboxylase67 (GAD67) expression in schizophrenia and bipolar disorder: A postmortem brain study. Archives of General Psychiatry, 57, 1061-1069.

doi:10.1001/archpsyc.57.11.1061

[11] Costa, E., Grayson, D.R., Mitchell, C.P., Tremolizzo, L., Veldic, M. and Guidotti, A. (2003) GABAergic cortical neuron chromatin as a putative target to treat schizophrenia vulnerability. Critical Reviews in Neurobiology, 15, 121-142. doi:10.1615/CritRevNeurobiol.v15.i2.20

[12] Bach, A.W., Lan, N.C., Johnson, D.L., Abell, C.W., Bembenek, M.E., Kwan, S.W., Seeburg, P.H. and Shih, J.C. (1988) cDNA cloning of human liver monoamine oxidase A and B: molecular basis of differences in enzymatic properties. Proceedings of the National Academy of Sciences of the United States of America, 85, 49344938. doi:10.1073/pnas.85.13.4934

[13] Chen, Z.Y., Powell, J.F., Hsu, Y.P., Breakefield, X.O. and Craig, I.W. (1992) Organization of the human monoamine oxidase genes and long-range physical map- ping around them. Genomics, 14, 75-82. doi:10.1016/S0888-7543(05)80286-1

[14] Westlund, K.N., Denney, R.M., Rose, R.M. and Abell, C.W. (1988) Localization of distinct monoamine oxidase $\mathrm{A}$ and monoamine oxidase $\mathrm{B}$ cell populations in human brainstem. Neuroscience, 25, 439-456. doi:10.1016/0306-4522(88)90250-3

[15] Murphy, D.L. and Wyatt, RJ. (1972) Reduced monoamine oxidase activity in blood platelets from schizophrenic patients. Nature, 238, 225-226. doi:10.1038/238225a0

[16] Wyatt, R.J., Murphy, D.L., Belmaker, R., Cohen, S., Donnelly, C.H. and Pollin, W. (1973) Reduced monoamine oxidase activity in platelets: A possible genetic marker for vulnerability to schizophrenia. Science, $\mathbf{1 7 9}$ 916-918. doi:10.1126/science.179.4076.916

[17] Collins, F.A., Murphy, D.L., Reiss, A.L. Sims, K.B., Lewis, J.G., Freund, L., Karoum, F., Zhu, D., Maumenee, I.H. and Antonarakis, S.E. (1992) Clinical, biochemical, and neuropsychiatric evaluation of a patient with a contiguous gene syndrome due to a microdeletion Xp11.3 including the Norrie disease locus and monoamine oxidase (MAOA and MAOB) genes. American Journal of Medical Genetics, 42, 127-134. doi:10.1002/ajmg.1320420126

[18] Brunner, H.G., Nelen, M., Breakefield, X.O., Ropers, H.H. and van, Oost, B.A. (1993) Abnormal behavior associated with a point mutation in the structural gene for monoamine oxidase A. Science, 262, 578-580. doi:10.1126/science. 8211186

[19] Newman, T.K., Syagailo, Y.V., Barr, C.S., Wendland, J.R., Champoux, M., Graessle, M., Suomi, S.J., Higley, J.D. and Lesch, K.P. (2005) Monoamine oxidase A gene promoter variation and rearing experience influences aggressive behavior in rhesus monkeys. Biological Psychiatry, 57, 167-172. doi:10.1016/j.biopsych.2004.10.012

[20] Alia-Klein, N., Goldstein, R.Z., Kriplani, A., Logan, J., Tomasi, D., Williams, B., Telang, F., Shumay, E., Biegon, A., Craig, I.W., Henn, F., Wang, G.J., Volkow, N.D. and Fowler, J.S. (2008) Brain monoamine oxidase A activity predicts trait aggression. The Journal of Neuroscience: The official journal of the Society for Neuroscience, $\mathbf{2 8}$, 5099-5104.

[21] Jiang, S., Xin, R., Lin, S., Qian, Y., Tang, G., Wang, D. and $\mathrm{Wu}, \mathrm{X}$. (2001) Linkage studies between attentiondeficit hyperactivity disorder and the monoamine oxidase genes. American Journal of Medical Genetics, 105, 783788. doi:10.1002/ajmg.10098

[22] Fossella, J., Sommer, T., Fan, J., Wu, Y., Swanson, J.M., Pfaff, D.W. and Posner, M.I. (2002) Assessing the molecular genetics of attention networks. BMC Neuroscience, 3, 14. doi:10.1186/1471-2202-3-14

[23] Lawson, D.C., Turic, D., Langley, K. Pay, H.M., Govan, C.F., Norton, N., Hamshere, M.L., Owen, M.J., O’Donovan, M.C. and Thapar, A. (2003) Association analysis of monoamine oxidase A and attention deficit hyperactivity disorder. American Journal of Medical Genetics Part B: Neuropsychiatric Genetics, 116, 84-89. doi:10.1002/ajmg.b.10002

[24] Heard, E., Clerc, P. and Avner, P. (1997) X-chromosome inactivation in mammals. Annual Review of Genetics, 31, 
571-610. doi:10.1146/annurev.genet.31.1.571

[25] Goto, T. and Monk, M. (1998) Regulation of X-chromosome inactivation in development in mice and humans. Microbiology and Molecular Biology Reviews, 62, 362378.

[26] Perlstein, W.M., Carter, C.S., Noll, D.C. and Cohen, J.D. (2001) Relation of prefrontal cortex dysfunction to working memory and symptoms in schizophrenia. The American Journal of Psychiatry, 158, 1105-1113. doi:10.1176/appi.ajp.158.7.1105

[27] Liddle, P.F., Lane, C.J. and Ngan, E.T. (2000) Immediate effects of risperidone on cortico-striato-thalamic loops and the hippocampus. The British Journal of Psychiatry, 177, 402-407. doi:10.1192/bjp.177.5.402

[28] Ikemoto, K., Kitahama, K., Maeda, T., Tokunaga, Y., Valatx, J.L., De, Maeyer, E. and Seif, I. (1997) Electron-microscopic study of $M A O B$-containing structures in the nucleus accumbens shell: Using MAOA-deficient transgenic mice. Brain Research, 771, 163-166. doi:10.1016/S0006-8993(97)00909-8

[29] Pietrobono, R., Pomponi, M.G., Tabolacci, E., Oostra, B., Chiurazzi, P. and Neri, G. (2002) Quantitative analysis of DNA demethylation and transcriptional reactivation of the FMR1 gene in fragile $X$ cells treated with 5-azadeoxycytidine. Nucleic Acids Research, 30, 3278-3285. doi:10.1093/nar/gkf434

[30] Carrel, L. and Willard, H.F. (2005) X-inactivation profile reveals extensive variability in $\mathrm{X}$-linked gene expression in females. Nature, 434, 400-404. doi: $10.1038 /$ nature 03479

[31] Wong, C.C., Caspi, A., Williams, B., Craig, I.W., Houts, R., Ambler, A., Moffitt, T.E. and Mill, J. (2010) A longitudinal study of epigenetic variation in twins. Epigenetics, 5, 516-26. doi:10.4161/epi.5.6.12226

[32] Wu, J.B., Chen, K., Li, Y., Lau, Y.F. and Shih, J.C. (2009) Regulation of monoamine oxidase A by the SRY gene on the Y chromosome. FASEB Journal, 23, 4029-4038. doi:10.1096/fj.09-139097

[33] Grayson, D.R., Jia, X., Chen, Y., Sharma, R.P., Mitchell, C.P., Guidotti, A. and Costa, E. (2005) Reelin promoter hypermethylation in schizophrenia. Proceedings of the National Academy of Sciences of the United States of America, 102, 9341-9346. doi:10.1073/pnas.0503736102

[34] Iwamoto, K., Bundo, M., Yamada, K., Takao, H., Iwayama-Shigeno, Y., Yoshikawa, T. and Kato, T. (2005) DNA methylation status of SOX10 correlates with its downregulation and oligodendrocyte dysfunction in schizophrenia. The Journal of Neuroscience, 25, 53765381. doi:10.1523/JNEUROSCI.0766-05.2005

[35] Thorpe, L.W., Westlund, K.N., Kochersperger, L.M., Abell, C.W. and Denney, R.M. (1987) Immunocytochemical localization of monoamine oxidases A and B in human peripheral tissues and brain. The Journal of Histochemistry and Cytochemistry, 35, 23-32. doi: $10.1177 / 35.1 .3025289$ 